\title{
Low-energy electron interactions with dimethyl disulphide
}

\author{
C. Matias ${ }^{1}$, A. Mauracher ${ }^{1}$, P. Scheier ${ }^{1}$, P. Limão-Vieira ${ }^{2, *}$ and S. Denifl ${ }^{1, *}$ \\ ${ }^{1}$ Institut für Ionenphysik und Angewandte Physik and Center of Molecular Biosciences Innsbruck, Universität \\ Innsbruck, Technikerstr. 25, A-6020 Innsbruck, Austria \\ ${ }^{2}$ Laboratório de Colisões Atómicas e Moleculares, CEFITEC, Departamento de Física, Faculdade de Ciências e \\ Tecnologia, Universidade Nova de Lisboa, 2829-516 Caparica, Portugal
}

\begin{abstract}
Electron attachment experiments have been performed with dimethyl disulphide, $\mathrm{C}_{2} \mathrm{H}_{6} \mathrm{~S}_{2}$, in the gas phase by means of a crossed electron-molecular beam experiment. Ion yields for 8 anions have been measured in the energy range from $\sim 0$ to $15 \mathrm{eV}$. Many of the dissociative electron attachment products observed at low energy arise from surprisingly complex reactions associated with multiple bond cleavages as well as structural and electronic rearrangement. Quantum chemical calculations on the electronic properties of $\mathrm{C}_{2} \mathrm{H}_{6} \mathrm{~S}_{2}$ have been performed in order to complement the experimental investigations.
\end{abstract}

Keywords: Dissociative electron attachment, Dimethyl disulphide, anion efficiency measurements, ab initio calculations

\footnotetext{
${ }^{*}$ Corresponding authors. Fax: +43 512 507-2932; Fax: + 351212948549

Email addresses: Stephan.Denifl@uibk.ac.at (S. Denifl); plimaovieira@fct.unl.pt (P. Limão-Vieira)
} 


\section{Introduction}

Several studies concerning the role of sulphur containing molecular species in the field of atmospheric chemistry have been reported (e.g. see Refs. [1, 2, 3] and references therein), whilst disulphide bond activation has been identified as relevant within the context of biochemical processes closely related to the stabilizing role on the structure of several proteins [4]. Within the disulphide containing peptides, conformational structures vary according to the disulphide-reduced against disulphide-oxidized forms [5], which in turn means different cellular functions [6, 7]. Reduction processes have been identified as crucial in biological systems, i.e. any additional theoretical and experimental studies will allow to fully understand the underlying molecular mechanisms of such processes. Here we are particularly interested on the role of resonant low-energy electron attachment to bare dimethyl disulphide (DMDS) molecules.

Dissociative electron attachment (DEA) experiments to DMDS yielding three fragment anions, namely $\mathrm{CH}_{2} \mathrm{~S}^{-}(46 \mathrm{u}), \mathrm{CH}_{3} \mathrm{~S}^{-}(47 \mathrm{u}), \mathrm{CH}_{3} \mathrm{~S}_{2}{ }^{-}(79 \mathrm{u})$ have been performed by Modelli et al. [8]. All fragments observed were formed in a single resonance below the electron energy of $1 \mathrm{eV}$. The by far dominant signal can be assigned to $\mathrm{SCH}_{2}{ }^{-}$formation. In a later study they further reported on the role of $\sigma^{*}$ shape resonances involving $\mathrm{S}-\mathrm{C}$ and $\mathrm{S}-\mathrm{S}$ antibonding levels in low-energy electron transmission spectroscopy experiments [9]. Rydberg electrontransfer spectroscopy and quantum chemical calculations on a series of saturated disulphides have shown nondissociative electron transfer at $0.2 \mathrm{eV}$ [10]. Recent multireference calculations on DMDS revealed that in the ground state the extra electron occupies the $\sigma^{*}(\mathrm{~S}-\mathrm{S})$ molecular orbital (MO) and upper in energy, there are two states at 202 and $210 \mathrm{~kJ} \mathrm{~mol}^{-1}$ (2.094 and $2.176 \mathrm{eV}$, respectively) whose singly occupied molecular orbitals are linear combinations of two non-bonding 3p-orbitals on each of the sulphur atoms [11]. These authors also point out evidence of another state at $278 \mathrm{~kJ} \mathrm{~mol}^{-1}(2.881 \mathrm{eV})$ where the unpaired electron is mainly located in the $\sigma(\mathrm{S}-\mathrm{S}) \mathrm{MO}$.

In the present work we investigate the negative ion formation upon electron attachment to dimethyl disulphide at low energies $(\sim 0-15 \mathrm{eV})$. In the study by Modelli et al. [8] negatively charged fragments formed upon electron capture to DMDS were analysed with a quadrupole mass spectrometer, while in the present study we utilized a sector field spectrometer. We note that the energy resolution in the previous experiment was substantially higher $(\sim 50 \mathrm{meV}$ compared to $\sim 1 \mathrm{eV}$ in the present work); however due to the higher electron current used here we gain sensitivity, which allows us to detect other fragment anions that have not been 
detected before. In the present work five out of eight measured fragments are reported for the first time.

\section{Experimental and quantum chemical calculations}

A two-sector-field mass spectrometer equipped with a standard Nier-type ion source was used in the present study. The electron energy spread is about $1 \mathrm{eV}$ (FWHM). The electron current is regulated to $10 \mu \mathrm{A}$, which is reached for electron energies higher than $2 \mathrm{eV}$. A voltage drop of $6 \mathrm{kV}$ is accelerating the ions to the sector fields. A liquid sample of DMDS, purchased from Sigma-Aldrich with a stated purity of $>99 \%$, was used for the present measurements. The sample was degassed by a repeated freeze-pump-thaw cycle prior to the experiments. During measurements the sample was kept at room temperature. The effusive molecular beam (capillary orifice with $1 \mathrm{~mm}$ diameter) was crossed at an angle of $60^{\circ}$ with the electron beam. The electron energy resolution and calibration were obtained by measuring the resulting ion yields as function of the electron energy for $\mathrm{SF}_{6}^{-}, \mathrm{F}^{-}$, and $\mathrm{F}_{2}^{-}$upon electron attachment to $\mathrm{SF}_{6}$ [12]. After mass selection in the magnetic sector field the ions pass a $1.4 \mathrm{~m}$ long field-free region before entering the electrostatic sector field. For the present investigation the mass resolution was kept at a minimum value of about $m / \Delta m \sim 1000$ by opening all slits to their maximum. The anions are detected with a channel electron multiplier operated in a pulse counting mode. Mass spectra were recorded at different electron energies and for all anions, identified as products of dissociative electron attachment to dimethyl disulphide, anion efficiency curves from $\sim 0$ to $15 \mathrm{eV}$ were measured.

For a better interpretation of the experimental findings, we carried out quantum chemical calculations on the electronic properties of DMDS. Full geometry optimization was achieved by employing MP2 perturbation theory in combination with Dunning's correlation consistent triple- $\zeta$ basis set augmented with diffuse functions (aug-cc-pVTZ). Adiabatic electron affinities and reaction thresholds were determined by employing various extrapolation schemes. We compare the results of G4(MP2) [13], CBS [14], W1 [15] and W1BD [16], which are all considered being highly accurate. The most accurate results are obtained with the W1BD method, which yields a root-mean-square deviation from the experiment of $(0.62 \pm 0.48) \mathrm{kcal} \mathrm{mol}^{-1}$, i.e. $(26.886 \pm 20.815) \mathrm{meV}$, in the $\mathrm{G} 2 / 97$ test set [16]. We find that all schemes yield very similar results. In Table 1 we list the reaction thresholds of all species involved, while in Table 2 we list the electron affinities. For the reaction thresholds listed in Table 1 we assumed the most simple single bond cleavages. These reaction thresholds can be lowered in case more stable neutral complexes are formed which will be discussed in the next 
section. The Gaussian 09 C.01 suite of programs was employed to carry out the calculations $[17]$.

\section{Results and discussion}

The ion efficiency curves of eight anions presently observed from dissociative electron attachment to dimethyl disulphide are shown in Fig. 1 - 3. Five of them are reported for the first time. The possible chemical compositions of the fragment anions observed and their corresponding resonance positions are listed in Table 3.

Before measuring the ion efficiency curves mass scans were also performed at electron energies between $\sim 0-10 \mathrm{eV}$. For illustration we show in Fig. 4 a mass spectrum recorded at the electron energy of $6 \mathrm{eV}$. Anions are formed in high abundance at this energy and relative intensities can be compared. For the mass scan recorded at the electron energy close to $0 \mathrm{eV}$ comparatively weak ion yields (around $1 \%$ of the anion $\mathrm{CH}_{2} \mathrm{~S}^{-}$) at masses $92 \mathrm{u}, 93 \mathrm{u}$ and $94 \mathrm{u}$ are present. At a first glance, these masses were thought to correspond to anions resulting from electron attachment to dimethyl disulphide, i.e. to the fragments $(\mathrm{M}-2 \mathrm{H})^{-},(\mathrm{M}-\mathrm{H})^{-}$, and the parent $(\mathrm{M})^{-}$, respectively. If the formation of the non-dissociated molecular ion would be observable, it would comprise the energy of the incoming electron and the electron affinity of the molecule, which could have resulted in a statistical intramolecular rearrangement delaying autodetachment [18]. The calculated adiabatic electron affinity of DMDS at W1BD level of theory is $0.08 \mathrm{eV}$ (electronic and zero point energy), which is associated with a noticeable change in the $\mathrm{S}-\mathrm{S}$ bond length from $2.06 \AA$ to $2.92 \AA$. Moreover, both $\mathrm{C}-\mathrm{S}-\mathrm{S}$ angles change from $103.6^{\circ}$ to $\sim 92^{\circ}$ by adding an additional electron. MP2/aug-cc-pVTZ yields a similar adiabatic electron affinity of $0.03 \mathrm{eV}$ and a vertical detachment energy of $1.64 \mathrm{eV}$ which is in good agreement with the experimental value of $1.75 \mathrm{eV}[10]$. However, the isotope pattern in the recorded mass spectra did not match any of the fragment anions proposed as well as the parent anion. In the latter case the ion yield at $94 \mathrm{u}$ hence cannot be assigned to the parent anion. In addition, all of these anions showed a resonance around $0.6 \mathrm{eV}$. The comparison with the thresholds obtained in the present calculations (see Table 1) leads to the conclusion that the formation of $(\mathrm{M}-2 \mathrm{H})^{-}$and $(\mathrm{M}-\mathrm{H})^{-}$is energetically not possible at the experimentally observed energies. In the calculation of the $(\mathrm{M}-2 \mathrm{H})^{-}$reaction threshold we calculated two cases, (i) removal of the two hydrogen atoms from one methyl-group and (ii) removal of one hydrogen atom from both methyl-groups. In the latter case the threshold is $6.45 \mathrm{eV}$, which is $0.10 \mathrm{eV}$ lower than the threshold to remove the hydrogen atoms from the same methyl-group. These reaction thresholds are lowered in case a hydrogen molecule is formed (binding energy 
of $\mathrm{H}_{2}$ is $4.48 \mathrm{eV}$, obtained with W1BD). Nevertheless the threshold energies values show still a discrepancy with the experimental observations $(\sim 0.6 \mathrm{eV})$ and the same occurs in the case of a dehydrogenated parent $(\mathrm{M}-\mathrm{H})^{-}$, where the calculations indicate an endothermic reaction with a thermodynamic threshold of $2.46 \mathrm{eV}$ (W1BD energies). Hence the experimental appearance energies of these fragments are a second indication (in addition to the isotope pattern) that the presence of ion yield at these three masses is due to an unknown impurity in the gas inlet.

The fragmentation patterns observed can be classified into three different groups according to their structural similarities: (1) Fragment anions $\mathrm{CH}_{n} \mathrm{~S}_{2}^{-}-$this group comprises masses $77 \mathrm{u}$ $\left(\mathrm{CHS}_{2}^{-}\right), 78 \mathrm{u}\left(\mathrm{CH}_{2} \mathrm{~S}_{2}^{-}\right), 79 \mathrm{u}\left(\mathrm{CH}_{3} \mathrm{~S}_{2}^{-}\right)$; (2) Fragment anions $\mathrm{CH}_{n} \mathrm{~S}^{-}$- includes masses $46 \mathrm{u}$ and $47 \mathrm{u}$ that correspond to $\mathrm{CH}_{2} \mathrm{~S}^{-}$and $\mathrm{CH}_{3} \mathrm{~S}^{-}$, respectively, which are by far the most dominant fragment anions. The last group (3) Fragment anions $\mathrm{S}_{2}^{-}, \mathrm{SH}^{-}, \mathrm{S}^{-}$- incorporates masses $64 \mathrm{u}, 33 \mathrm{u}$ and $32 \mathrm{u}$, respectively.

\subsection{Ion efficiency curves}

The formation of $\mathrm{CH}_{2} \mathrm{~S}_{2}{ }^{-}$(mass $78 \mathrm{u}$ ) ion is just restricted to a feature close to $0.3 \mathrm{eV}$, while all other fragment ions show more extended resonance profiles (see Table 3). This can be due to the fact that even the $0.3 \mathrm{eV}$ resonance of $\mathrm{CH}_{2} \mathrm{~S}_{2}{ }^{-}$has a very weak yield $(\sim 1 \%)$ when compared to the most intense resonances of other fragment anions. Hence any $\mathrm{CH}_{2} \mathrm{~S}_{2}{ }^{-}$signal at higher electron energies may be below the detection limit of the apparatus.

Within the variety of resonant structures in the entire energy range from 0 to $15 \mathrm{eV}$ the anion intensity of most of the fragments is concentrated within three energy regions, in the range below 2, 4-6 and 6-10 eV. For example, the shape and position for the resonances of $\mathrm{S}^{-}$and $\mathrm{S}_{2}{ }^{-}$fragments are very similar, which indicate that these anions may have common precursor transient anion states. Another group of anions that show a similar behaviour are $\mathrm{CH}_{2} \mathrm{~S}^{-}$, $\mathrm{CH}_{3} \mathrm{~S}^{-}$and $\mathrm{CH}_{3} \mathrm{~S}_{2}^{-}$, which exhibit comparable values for the resonances, both at lower and higher electron energies.

The temporary negative ions (TNIs) generated at low energy $(<2 \mathrm{eV})$ can be assigned as shape resonances involving $\sigma^{*}$ antibonding orbitals. Modelli et al. [8] calculated that the lowest $\sigma^{*}$ antibonding orbital of the $(\mathrm{S}-\mathrm{S})$ bond is at $1.04 \mathrm{eV}$, which is in good agreement with our experimental results. Also, it is likely that the resonances at higher energies can be characterized as core-excited resonances with possible contributions of high energy shape resonances. The states mentioned in the introduction at $2.094 \mathrm{eV}, 2.176 \mathrm{eV}$ and $2.881 \mathrm{eV}$ [11] 
may not be involved in the anion formation, since the resonances appear at substantial higher energies.

\subsubsection{Fragment anions $\mathrm{CH}_{n} \mathrm{~S}_{2}^{-}, n=1,2,3$}

The resonant structures of these fragment anions are shown in Fig. $1\left(\mathrm{CH}_{3} \mathrm{~S}_{2}{ }^{-}\right.$, blue triangles) and Fig. $3\left(\mathrm{CH}_{2} \mathrm{~S}_{2}{ }^{-}\right.$, lower panel, and $\mathrm{CHS}_{2}{ }^{-}$, upper panel) with their energy positions listed in Table 3. $\mathrm{CH}_{3} \mathrm{~S}_{2}{ }^{-}$ion formation most probably proceeds via the following reaction:

$\mathrm{e}^{-}+\mathrm{M} \rightarrow(\mathrm{M})^{\#-} \rightarrow\left[\mathrm{M}-\mathrm{CH}_{3}\right]^{-}+\mathrm{CH}_{3}$

The $\mathrm{CH}_{3} \mathrm{~S}_{2}{ }^{-}$fragment anion $(79 \mathrm{u})$ has been reported previously by Modelli et al. [8] with a single resonance feature peaking at $0.8 \mathrm{eV}$, in good agreement with the present experiment albeit the present modest electron energy resolution of $\sim 1 \mathrm{eV}$. The resonances observed at 9.2 and $10 \mathrm{eV}$ for $\mathrm{CH}_{3} \mathrm{~S}_{2}^{-}$and $\mathrm{CHS}_{2}^{-}$, respectively, (Table 3) can be assigned likely to electronically excited TNI states (including Rydberg excitation), which may decompose via one fragment anion plus one or more neutrals. Taking W1BD energy values of the products and reactant, reaction (1) is endothermic by $0.72 \mathrm{eV}$, which corresponds to the experimental value bearing in mind the current electron energy resolution. The intensities of the ion yields at 80 and $81 \mathrm{u}$ are within the expected isotope ratio relative to $79 \mathrm{u}$.

The $\mathrm{CH}_{2} \mathrm{~S}_{2}{ }^{-}$fragment anion $(78 \mathrm{u}$ ) has a calculated threshold formation of $4.46 \mathrm{eV}$. However if its formation proceeds through the formation of $\mathrm{CH}_{4}$, the threshold is lowered by $4.48 \mathrm{eV}$ (binding energy of $\mathrm{H}$ to $\mathrm{CH}_{3}$ ). Therefore the reaction will be slightly exothermic by $0.02 \mathrm{eV}$, obtained with a W1BD level of theory. This result matches with the experimental data obtained, where we find the peak at the electron energy of $0.3 \mathrm{eV}$. Hence, we propose that the formation of the fragment anion $\mathrm{CH}_{2} \mathrm{~S}_{2}{ }^{-}$proceeds through:

$\mathrm{e}^{-}+\mathrm{M} \rightarrow(\mathrm{M})^{\#-} \rightarrow\left[\mathrm{M}-\mathrm{CH}_{4}\right]^{-}+\mathrm{CH}_{4}$

Concerning the fragment anion $\mathrm{CHS}_{2}{ }^{-}(77 \mathrm{u})$, we ascribe the first peak close to $0 \mathrm{eV}$ to form by electron attachment to thermal decomposition products of DMDS. The latter are likely generated in reactions of DMDS with the heated surfaces of the ion source or the hot filament. The calculated threshold indicates formation only above $7.43 \mathrm{eV}$, which is in agreement with the resonance observed at $10 \mathrm{eV}$. At this electron energy, the fragment anion is formed by 
cleavage of the central S-S bond and the additional break of two $\mathrm{H}-\mathrm{C}$ bond and the formation of a neutral $\mathrm{CH}_{3}$ :

$\mathrm{e}^{-}+\mathrm{M} \rightarrow(\mathrm{M})^{\#-} \rightarrow \mathrm{CHS}_{2}^{-}+\mathrm{CH}_{3}+2 \mathrm{H}$

We note that another indication of thermal decomposition was the increase of the relative height of the zero eV peak when the ion source temperature was raised. Analogous behaviour was observed for the near zero eV peak of $\mathrm{S}_{2}{ }^{-}, \mathrm{SH}^{-}$and $\mathrm{S}^{-}$, i.e. we expect thermal decomposition of the neutral before electron capture to be involved in the formation of these resonances (see below).

\subsubsection{Fragment anions $\mathrm{CH}_{n} \mathrm{~S}^{-}, n=2,3$}

$\mathrm{CH}_{2} \mathrm{~S}^{-}$and $\mathrm{CH}_{3} \mathrm{~S}^{-}$are by far the most dominant fragment anions in DEA to dimethyl sulphide. The resonances yielding $\mathrm{CH}_{3} \mathrm{~S}^{-}$and $\mathrm{CH}_{2} \mathrm{~S}^{-}$ions are listed in Table 3 and shown in Fig. 1. The formation of these anions has been reported before but restricted to a low energy resonance peaking at 0.86 and $0.67 \mathrm{eV}$, respectively [8]. We observe good agreement with this previous work concerning these low energy resonances, since we obtain a peak at $0.7 \mathrm{eV}$ for $\mathrm{CH}_{3} \mathrm{~S}^{-}$and $0.3 \mathrm{eV}$ for $\mathrm{CH}_{2} \mathrm{~S}^{-}$. In addition we observe other resonance features at higher electron energies $(>4 \mathrm{eV})$. The formation of these anions requires the cleavage of the $\mathrm{S}-\mathrm{S}$ bond and $\mathrm{C}-\mathrm{H}$ bonds in the precursor ion, where such mechanism is remarkable at low incident electron energies. Interesting to note is that in $\mathrm{CH}_{3} \mathrm{~S}^{-}$the excess electron is localized at the $\mathrm{S}$ atom (Fig. 5C, left panel), whereas for $\mathrm{CH}_{2} \mathrm{~S}^{-}$the MO 13 is mainly $\pi^{*}(\mathrm{~S}=\mathrm{C})$ in character, which is delocalized over the whole fragment (Fig. 5C, middle panel). This may explain the higher anionic yield for this fragment. For $\mathrm{CH}_{2} \mathrm{~S}^{-}$the relative percentage of the isotope at $48 \mathrm{u}$ to $46 \mathrm{u}$ is $4.4 \%$ and the measured one is $4.4 \%$, and for $\mathrm{CH}_{3} \mathrm{~S}^{-}$the relative percentage of $49 \mathrm{u}$ to $47 \mathrm{u}$ is $4.4 \%$ and the measured one is $4.2 \%$, i.e. both are in good agreement. The reaction yielding $\mathrm{CH}_{3} \mathrm{~S}^{-}$formation is endothermic with a calculated threshold at $0.90 \mathrm{eV}$ which is in reasonable good agreement with the experimental value. The threshold for $\mathrm{CH}_{2} \mathrm{~S}^{-}$formation is $4.45 \mathrm{eV}$. Assuming that a neutral $\mathrm{HSCH}_{3}$ complex is formed this reaction value is lowered by $3.72 \mathrm{eV}$ (binding energy obtained at $\mathrm{W} 1 \mathrm{BD}$ ), which is in agreement with the present experimental results.

\subsubsection{Fragment anions $S_{2}^{-}, S H$ and $S$}


The DEA anionic yields for $\mathrm{S}^{-}$and $\mathrm{S}_{2}^{-}$are shown in Fig. 2; the observed resonance positions are listed in Table 3. Both fragment anions do not exhibit any abundant low energy resonance $\left(<4 \mathrm{eV}\right.$ ), since the weak feature close to $0 \mathrm{eV}$ (which is more evident for $\mathrm{S}_{2}{ }^{-}$) is attributed to an artefact (thermal decomposition) as mentioned above. The relative percentages of $32 \mathrm{u}: 34 \mathrm{u}$ and $64 \mathrm{u}: 66 \mathrm{u}$ are approximately 4.3\% and 10.6\%, respectively, matching very well the natural abundance. The sulphur anion $\mathrm{S}^{-}$is formed by cleavage of $\mathrm{S}-\mathrm{S}$ and $\mathrm{S}-\mathrm{C}$ bonds in the target molecule, whilst $\mathrm{S}_{2}{ }^{-}$results from the breaking of the two $\mathrm{S}-\mathrm{C}$ bonds. The calculated threshold energies for the formation of $\mathrm{S}^{-}$and $\mathrm{S}_{2}^{-}$are $3.78 \mathrm{eV}$ and $2.87 \mathrm{eV}$, respectively. The calculated threshold value for $\mathrm{S}_{2}{ }^{-}$fits with the presence of a resonance at 5.4 $\mathrm{eV}$ obtained in the present experiment. For the calculated value mentioned only simple bond cleavages are considered and no formation of any new neutral complexes. Instead, in the case of neutral $\mathrm{CH}_{3} \mathrm{SCH}_{3}$ formation the binding energy of $3.13 \mathrm{eV}$ is gained and thus the formation of $\mathrm{S}^{-}$has an energy threshold of $0.65 \mathrm{eV}$ (W1BD level of theory). This value agrees with the experimental results obtained for the first resonance of $\mathrm{S}^{-}(2.4 \mathrm{eV})$. The calculated threshold value at $3.78 \mathrm{eV}$ may be assigned to the second resonance of $\mathrm{S}^{-}$located at $5.5 \mathrm{eV}$.

The anion $\mathrm{SH}^{-}(33 \mathrm{u})$ shows a low energy resonance close to $0 \mathrm{eV}$ (see Fig. 2), which we ascribe to thermal decomposition, and three other less intense features at 1.9, 5.8 and $9.3 \mathrm{eV}$. $\mathrm{SH}^{-}$results from the cleavage of several bonds ( $-\mathrm{S}, \mathrm{S}-\mathrm{C}$ and $\left.\mathrm{C}-\mathrm{H}\right)$ and intramolecular $\mathrm{H}$ atom transfer. The present calculations show that the singly occupied molecular orbital of the anion has a node in the $\mathrm{S}-\mathrm{H}$ bond with the extra charge sitting at the sulphur atom (Fig. $5 \mathrm{C}$, right panel). The lowest calculated energetic threshold for $\mathrm{SH}^{-}$formation is $0.76 \mathrm{eV}$ assuming that a neutral $\mathrm{H}_{2} \mathrm{CSCH}_{3}$ complex is formed. In case that neutral $\mathrm{CH}_{3}$ and $\mathrm{SCH}_{2}$ are formed the threshold value increases to $2.08 \mathrm{eV}$, which, though in fair agreement, may be assigned to the resonance obtained at $1.9 \mathrm{eV}$. The reaction involving neutral $\mathrm{CH}_{2}$ and $\mathrm{SCH}_{3}$ formation has the highest threshold of $4.64 \mathrm{eV}$, which can be ascribed to the presence of a measured resonance at $5.8 \mathrm{eV}$.

\section{Conclusions}

In the present DEA study with dimethyl disulphide anion yields have been measured in the electron energy range of $\sim 0-15 \mathrm{eV}$. In total, eight fragments were observed through the DEA process within the sensitivity limit of the apparatus. From all the fragments detected, five fragment anions have been detected for the first time in comparison to previous DEA studies with $\mathrm{C}_{2} \mathrm{H}_{6} \mathrm{~S}_{2}$. For the three previously reported fragment anions $\left(\mathrm{CH}_{2} \mathrm{~S}^{-}, \mathrm{CH}_{3} \mathrm{~S}^{-}, \mathrm{CH}_{3} \mathrm{~S}_{2}{ }^{-}\right)$we observe good agreement in the peak positions $<1 \mathrm{eV}$. Furthermore, we observe here that the 
DEA mechanism is also operative at higher electron energies leading to these anions. With the support of the quantum chemical calculations it was possible to assign the chemical composition of neutral and negatively charged fragments to the different resonances experimentally observed. We obtain a good agreement between the values derived upon W1BD and the experimental data.

\section{Acknowledgements}

This work has been supported by the Fonds zur Förderung der wissenschaftlichen Forschung (FWF Project No. P22665), Wien, the European Commission, Brussels, via COST Action MP1002 programme Nanoscale Insights into Ion Beam Cancer Therapy (Nano-IBCT), the Austrian Ministry of Science BMWF as part of the Konjunkturpaket II and as part of the UniInfrastrukturprogramm of the Focal Point Scientific Computing at the University of Innsbruck. A. M. acknowledges a grant from the Nachwuchsförderung of the University of Innsbruck. PL-V acknowledges partial funding from the research grants PEstOE/FIS/UI0068/2014 and PTDC/FIS/ATO/1832/2012. 


\section{References}

[1] V. Aquilanti, M. Ragni, A. C. P. Bitencourt, G. S. Maciel, F. V. Prudente, J. Phys. Chem. A 113 (2009) 3804.

[2] P. Limão-Vieira, S. Eden, P. A. Kendall, N. J. Mason, S. V. Hoffmann, Chem. Phys. Lett. 366 (2002) 343.

[3] E. A. Drage, P. Cahillane, S. V. Hoffmann, N. J. Mason, P. Limão-Vieira, Chem. Phys. 331 (2007) 447.

[4] S. D. Dai, C. Schwendtmayer, P. Schurmann, S. Ramaswamy, H. Eklund, Science 287 (2000) 655 .

[5] G. A. Rickard, J. Bergès, C. Houeè-Levin, A. Rauk, J. Phys. Chem. B 112 (2008) 5774.

[6] H. Nakamura, K. Nakamura, J. Yodoi, Annu. Rev. Immunol. 15(1997) 351.

[7] A. Baker, C. M. Payne, M. M. Briehl, G. Powis, Cancer Res. 57 (1997) 5162.

[8] A. Modelli, D. Jones, G. Distefano, M. Tronc, Chem. Phys. Lett. 181 (1991) 361.

[9] C. Dezarnaud-Dandine, F. Bournel, M. Tronc, D. Jones, A. Modelli, J. Phys. B: At. Mol. Opt. Phys. 31 (1998) L497.

[10] S. Carles, F. Lecomte, J. P. Schermann, C. Desfrançois, S. Xu, J. M. Nilles, K. H. Bowen, J. Bergès, C. Houeè-Levin, J. Phys. Chem. A 105 (2001) 5622.

[11] J. A. Gámez, L. Serrano-Andrés, M. Yáñez, Int. J. Quantum Chem. 111 (2011) 3316.

[12] M. Fenzlaff, R. Gerhard, E. Illenberger, J. Chem. Phys. 88 (1), 149 (1988).

[13] L. A. Curtiss, P. C. Redfern, K. Raghavachari, J. Chem. Phys. 127 (2007) 124105.

[14] J. A. Montgomery Jr., M. J. Frisch, J. W. Ochterski, G. A. Petersson, J. Chem. Phys. 112 (2000) 6532-42.

[15] J. M. L. Martin, G. de Oliveira, J. Chem. Phys. 111 (1999) 1843-56.

[16] E. C. Barnes, G. A. Petersson, J. A. Montgomery Jr., M. J. Frisch, J. M. L. Martin, J. Chem. Theor. Comput. 5 (2009) 2687.

[17] Gaussian 09, Revision C.01, M. J. Frisch, G. W. Trucks, H. B. Schlegel, G. E. Scuseria, M. A. Robb, J. R. Cheeseman, G. Scalmani, V. Barone, B. Mennucci, G. A. Petersson, H. Nakatsuji, M. Caricato, X. Li, H. P. Hratchian, A. F. Izmaylov, J. Bloino, G. Zheng, J. L. Sonnenberg, M. Hada, M. Ehara, K. Toyota, R. Fukuda, J. Hasegawa, M. Ishida, T. Nakajima, Y. Honda, O. Kitao, H. Nakai, T. Vreven, J. A. Montgomery, Jr., J. E. Peralta, F. Ogliaro, M. Bearpark, J. J. Heyd, E. Brothers, K. N. Kudin, V. N. Staroverov, R. Kobayashi, J. Normand, K. Raghavachari, A. Rendell, J. C. Burant, S. S. Iyengar, J. Tomasi, M. Cossi, N. Rega, J. M. Millam, M. Klene, J. E. Knox, J. B. Cross, V. Bakken, C. Adamo, J. Jaramillo, R. Gomperts, 
R. E. Stratmann, O. Yazyev, A. J. Austin, R. Cammi, C. Pomelli, J. W. Ochterski, R. L. Martin, K. Morokuma, V. G. Zakrzewski, G. A. Voth, P. Salvador, J. J. Dannenberg, S. Dapprich, A. D. Daniels, Ö. Farkas, J. B. Foresman, J. V. Ortiz, J. Cioslowski, and D. J. Fox, Gaussian, Inc., Wallingford CT, 2009.

[18] E. Illenberger, in: C.-Y. Ng (Ed.), Advanced Series in Physical Chemistry, vol. 10B, World Scientific, Singapore, 2000, pp. 1063-1160. 
Figure 1 - Anion efficiency curves for the most intense anions formed upon dissociative electron attachment to dimethyl disulphide assigned to $\mathrm{CH}_{2} \mathrm{~S}^{-}$(black solid line), $\mathrm{CH}_{3} \mathrm{~S}^{-}$(red circles) and $\mathrm{CH}_{3} \mathrm{~S}_{2}^{-}$(blue triangles), respectively. The width of the electron energy distribution is about $1 \mathrm{eV}$.

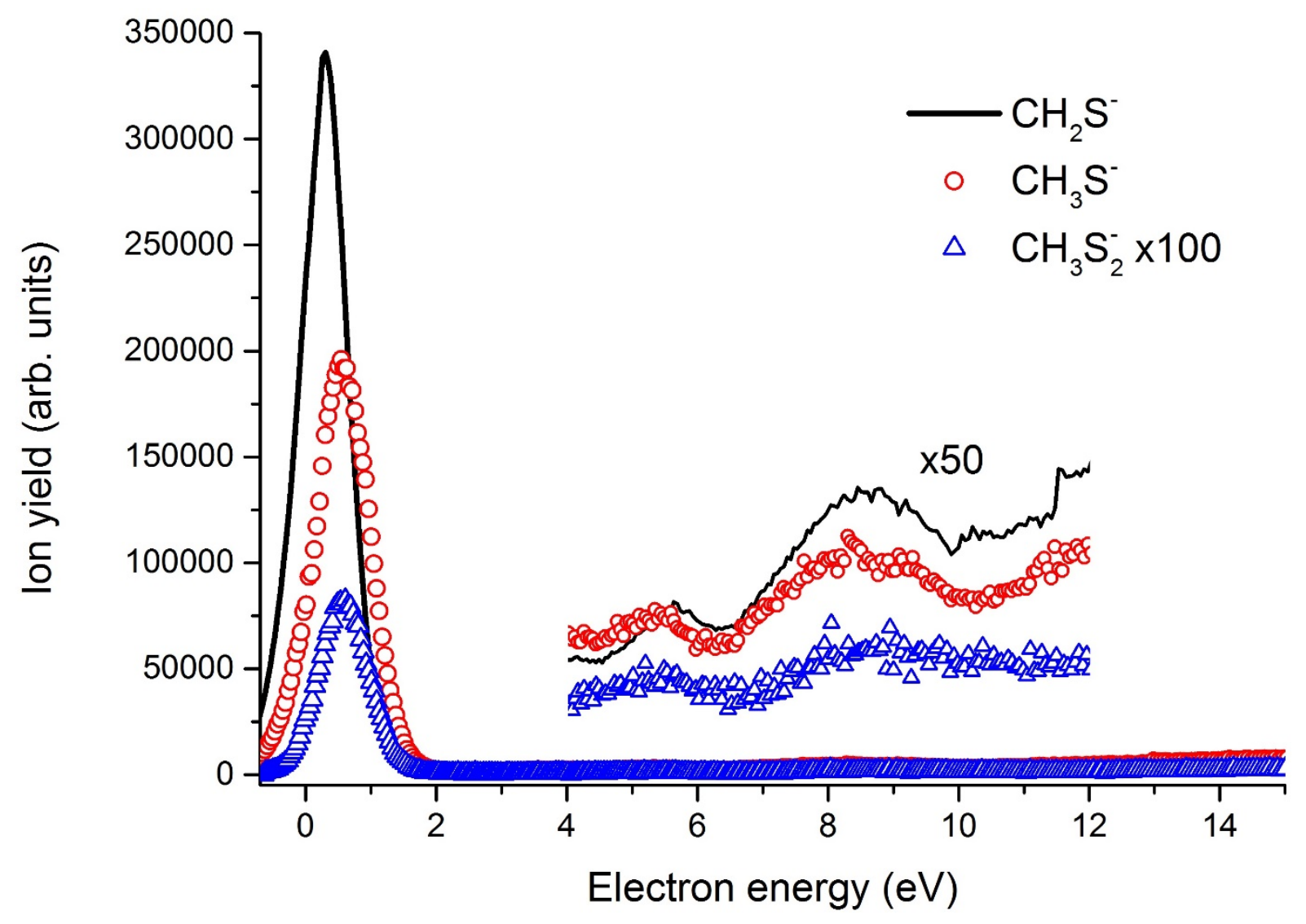


Figure 2 - Anion efficiency curves of the fragment ions $\mathrm{S}^{-}$(upper panel), $\mathrm{S}_{2}^{-}$(middle panel), $\mathrm{SH}^{-}$(lower panel), respectively. The width of the electron energy distribution is about $1 \mathrm{eV}$.

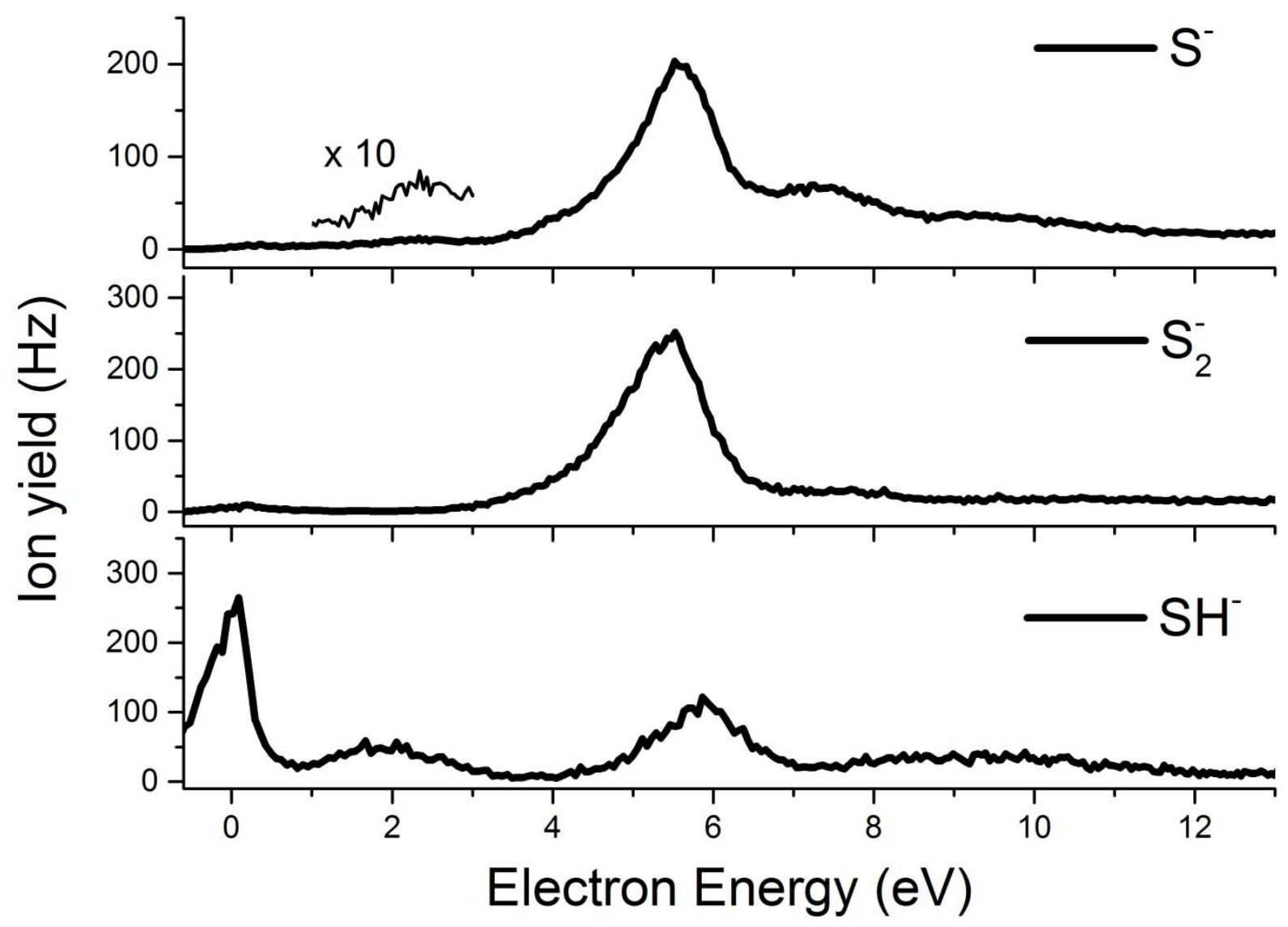


Figure 3 - Anion efficiency curves of $\mathrm{CHS}_{2}{ }^{-}$(middle panel) and $\mathrm{CH}_{2} \mathrm{~S}_{2}{ }^{-}$(lower panel). The width of the electron energy distribution is about $1 \mathrm{eV}$.

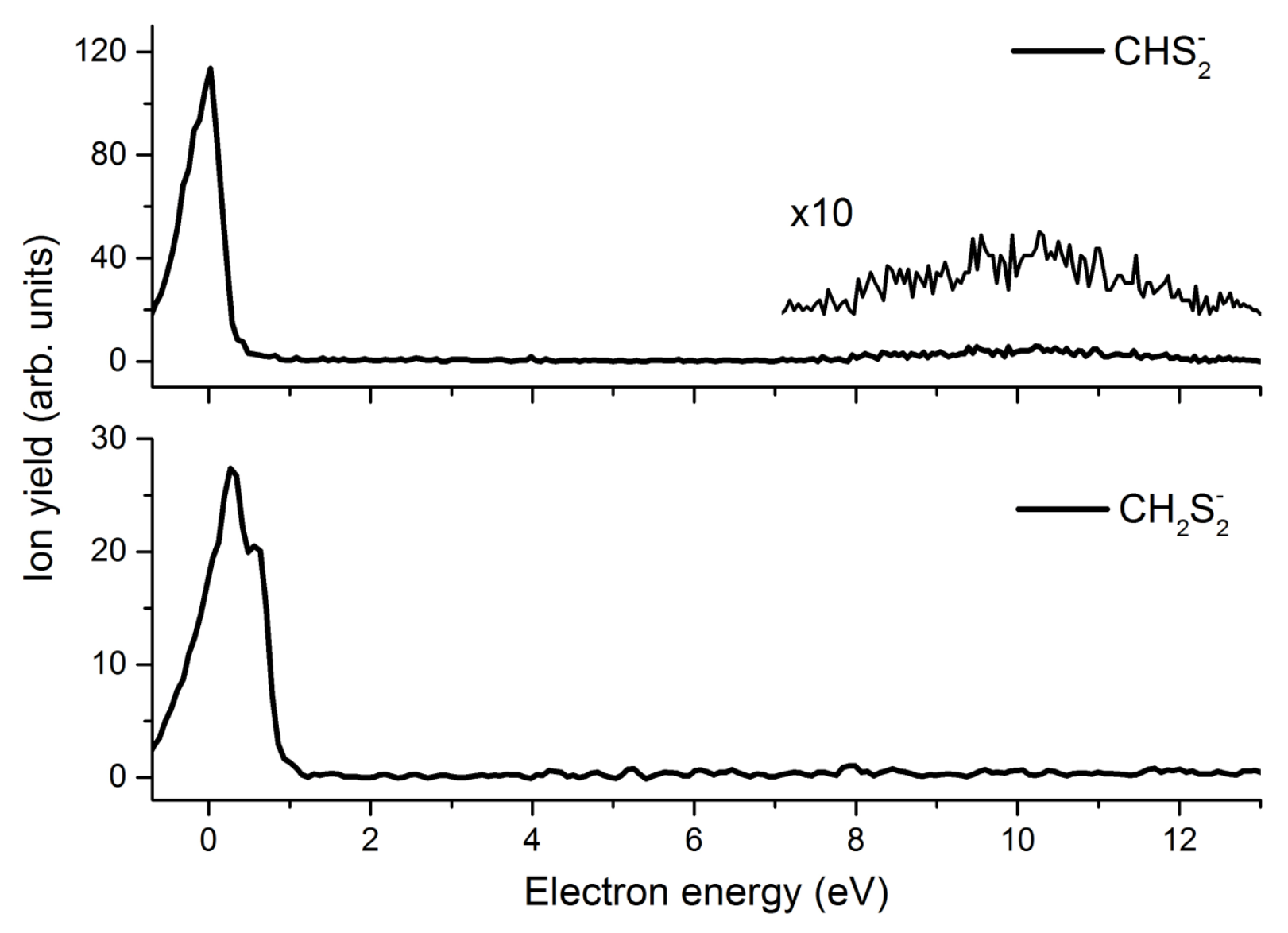


Figure 4 - Mass spectrum obtained at the electron energy of $6 \mathrm{eV}$. The ion peaks are labelled according to their chemical composition. For further details see text.

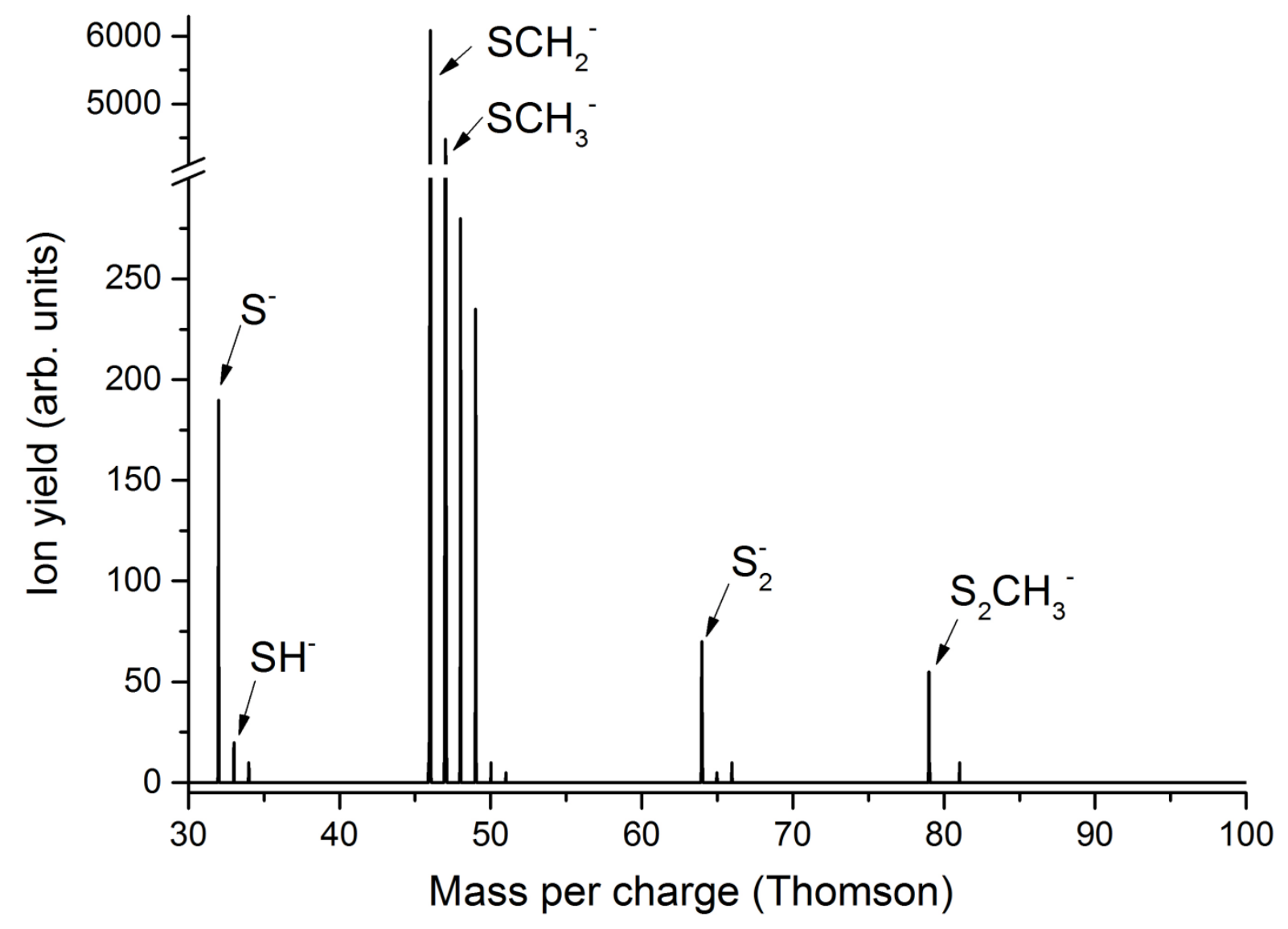


Figure 5 - Optimized structures depicted for dimethyl disulphide as neutral (A left panel) and negatively charged (B left panel) molecule. Shown are also the highest occupied molecular orbital of the neutral molecule (A right panel, MO 25) and the singly occupied molecular orbital of the anion (B right panel, MO 26). The highest occupied molecular orbitals for $\mathrm{CH}_{3} \mathrm{~S}^{-}$(C left panel, MO 13), for $\mathrm{CH}_{2} \mathrm{~S}^{-}$(C middle panel, MO 13) and for $\mathrm{SH}^{-}$(C right panel, MO 10) are shown as well. All results were obtained at MP2/aug-cc-pVTZ level of theory.

A

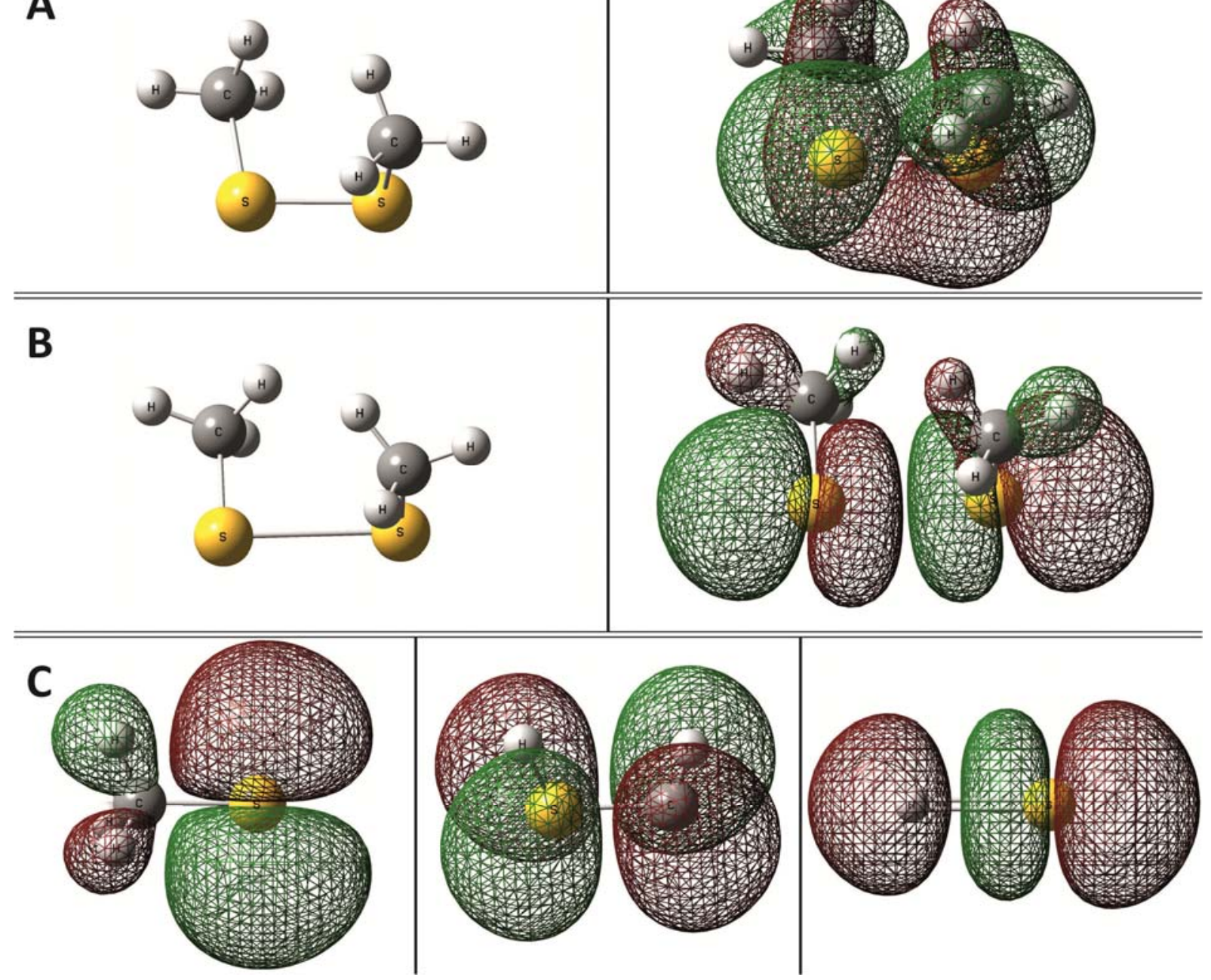


Table 1 - Reaction thresholds calculated using various high-level extrapolation schemes. See text for further explanations.

\begin{tabular}{|l||c|c|c|c|}
\hline \multirow{2}{*}{$\mathrm{H}_{3} \mathrm{CS}_{2} \mathrm{CH}_{3}+\mathrm{e}^{-} \rightarrow$} & \multicolumn{4}{|c|}{ Reaction threshold (eV) } \\
\cline { 2 - 5 } & $\mathrm{G} 4(\mathrm{MP} 2)$ & $\mathrm{CBS}$ & $\mathrm{W} 1$ & $\mathrm{~W} 1 \mathrm{BD}$ \\
\hline \hline $\mathrm{H}_{3} \mathrm{CS}_{2} \mathrm{CH}_{3}^{-}$ & 0 & 0 & 0 & 0 \\
\hline $\mathrm{H}_{3} \mathrm{CS}_{2} \mathrm{CH}_{2}^{-}+\mathrm{H}$ & 2.33 & 2.38 & 2.46 & 2.46 \\
\hline $\mathrm{H}_{3} \mathrm{CS}_{2} \mathrm{CH}^{-}+2 \mathrm{H}$ & 6.76 & 6.44 & 6.53 & 6.55 \\
\hline $\mathrm{H}_{2} \mathrm{CS}_{2} \mathrm{CH}_{2}{ }^{-}+2 \mathrm{H}$ & 6.31 & 6.34 & 6.42 & 6.45 \\
\hline $\mathrm{CH}_{3} \mathrm{~S}_{2}^{-}+\mathrm{CH}_{3}$ & 0.70 & 0.70 & 0.72 & 0.72 \\
\hline $\mathrm{CH}_{2} \mathrm{~S}_{2}^{-}+\mathrm{CH}_{3}+\mathrm{H}$ & 4.43 & 4.45 & 4.46 & 4.46 \\
\hline $\mathrm{CHS}_{2}{ }^{-}+\mathrm{CH}_{3}+2 \mathrm{H}$ & 7.28 & 7.38 & 7.43 & 7.43 \\
\hline $\mathrm{S}_{2}^{-}+2 \mathrm{CH}_{3}$ & 2.86 & 2.85 & 2.86 & 2.87 \\
\hline $\mathrm{CH}_{3} \mathrm{~S}^{-}+\mathrm{SCH}_{3}$ & 0.88 & 0.88 & 0.90 & 0.90 \\
\hline $\mathrm{CH}_{2} \mathrm{~S}^{-}+\mathrm{SCH}_{3}+\mathrm{H}$ & 4.41 & 4.41 & 4.45 & 4.45 \\
\hline $\mathrm{SH}^{-}+\mathrm{SCH}_{3}+\mathrm{CH}_{2}$ & 4.65 & 4.32 & 4.63 & 4.64 \\
\hline $\mathrm{S}^{-}+\mathrm{SCH}_{3}+\mathrm{CH}_{3}$ & 3.81 & 3.79 & 3.78 & 3.78 \\
\hline
\end{tabular}


Table 2 - (Adiabatic) Electron affinities for the molecular fragments forming anions observed in the experiment using various high-level extrapolation schemes. See text for further explanations.

\begin{tabular}{|c||c|c|c|c|}
\hline \multicolumn{1}{|c||}{} & \multicolumn{4}{c|}{ (Adiabatic) Electron affinity (eV) } \\
\cline { 2 - 5 } & $\mathrm{G} 4(\mathrm{MP} 2)$ & $\mathrm{CBS}$ & $\mathrm{W} 1$ & $\mathrm{~W} 1 \mathrm{BD}$ \\
\hline $\mathrm{H}_{3} \mathrm{CS}_{2} \mathrm{CH}_{3}$ & 0.18 & 0.20 & 0.08 & 0.08 \\
\hline $\mathrm{H}_{3} \mathrm{CS}_{2} \mathrm{CH}_{2}$ & 1.69 & 1.73 & 1.63 & 1.63 \\
\hline $\mathrm{H}_{3} \mathrm{CS}_{2} \mathrm{CH}$ & 0.65 & 1.04 & 1.02 & 1.00 \\
\hline $\mathrm{H}_{2} \mathrm{CS}_{2} \mathrm{CH}_{2}$ & 1.19 & 1.24 & 1.20 & 1.17 \\
\hline $\mathrm{CH}_{3} \mathrm{~S}_{2}$ & 1.76 & 1.81 & 1.78 & 1.77 \\
\hline $\mathrm{CH}_{2} \mathrm{~S}_{2}$ & 1.04 & 1.09 & 1.12 & 1.13 \\
\hline $\mathrm{CHS}_{2}$ & 3.08 & 2.98 & 2.86 & 2.87 \\
\hline $\mathrm{S}_{2}$ & 1.70 & 1.70 & 1.66 & 1.67 \\
\hline $\mathrm{CH}_{3} \mathrm{~S}$ & 1.86 & 1.90 & 1.87 & 1.87 \\
\hline $\mathrm{CH}_{2} \mathrm{~S}$ & 0.46 & 0.50 & 0.51 & 0.51 \\
\hline $\mathrm{SH}_{\mathrm{SH}}$ & 2.32 & 2.37 & 2.35 & 2.35 \\
\hline 2.04 & 2.09 & 2.08 & 2.08 \\
\hline
\end{tabular}


Table 3 - Peak positions for all anions of dimethyl disulphide obtained in the present experiment compared to previous studies [8].

\begin{tabular}{|c|c||c|c|c|c|c|c|c||c|}
\hline $\begin{array}{c}\text { Mass } \\
(\mathrm{Da})\end{array}$ & \multicolumn{1}{|c||}{ Assignment } & \multicolumn{7}{|c||}{ Peak position (eV) } & [8] \\
\hline \hline 79 & $\mathrm{CH}_{3} \mathrm{~S}_{2}^{-}$ & 0.6 & - & - & 5.1 & - & 9.2 & - & 0.8 \\
\hline 78 & $\mathrm{CH}_{2} \mathrm{~S}_{2}^{-}$ & 0.3 & - & - & - & - & - & - & - \\
\hline 77 & $\mathrm{CHS}_{2}^{-}$ & $0{ }^{*}$ & - & - & - & - & - & 10.0 & - \\
\hline 64 & $\mathrm{~S}_{2}^{-}$ & $0.2^{*}$ & - & - & 5.4 & 7.3 & - & 10.5 & - \\
\hline 47 & $\mathrm{CH}_{3} \mathrm{~S}^{-}$ & 0.7 & - & 3.8 & 5.3 & - & 8.6 & - & 0.86 \\
\hline 46 & $\mathrm{CH}_{2} \mathrm{~S}^{-}$ & 0.3 & - & 3.7 & 5.6 & - & 8.7 & - & 0.67 \\
\hline 33 & $\mathrm{SH}^{-}$ & 0 & 1.9 & - & 5.8 & - & 9.3 & - & - \\
\hline 32 & $\mathrm{~S}^{-}$ & $0.5^{*}$ & 2.4 & - & 5.5 & 7.2 & - & 9.8 & - \\
\hline
\end{tabular}

This resonance is due to thermal decomposition (see text). 


\section{Graphical Abstract}

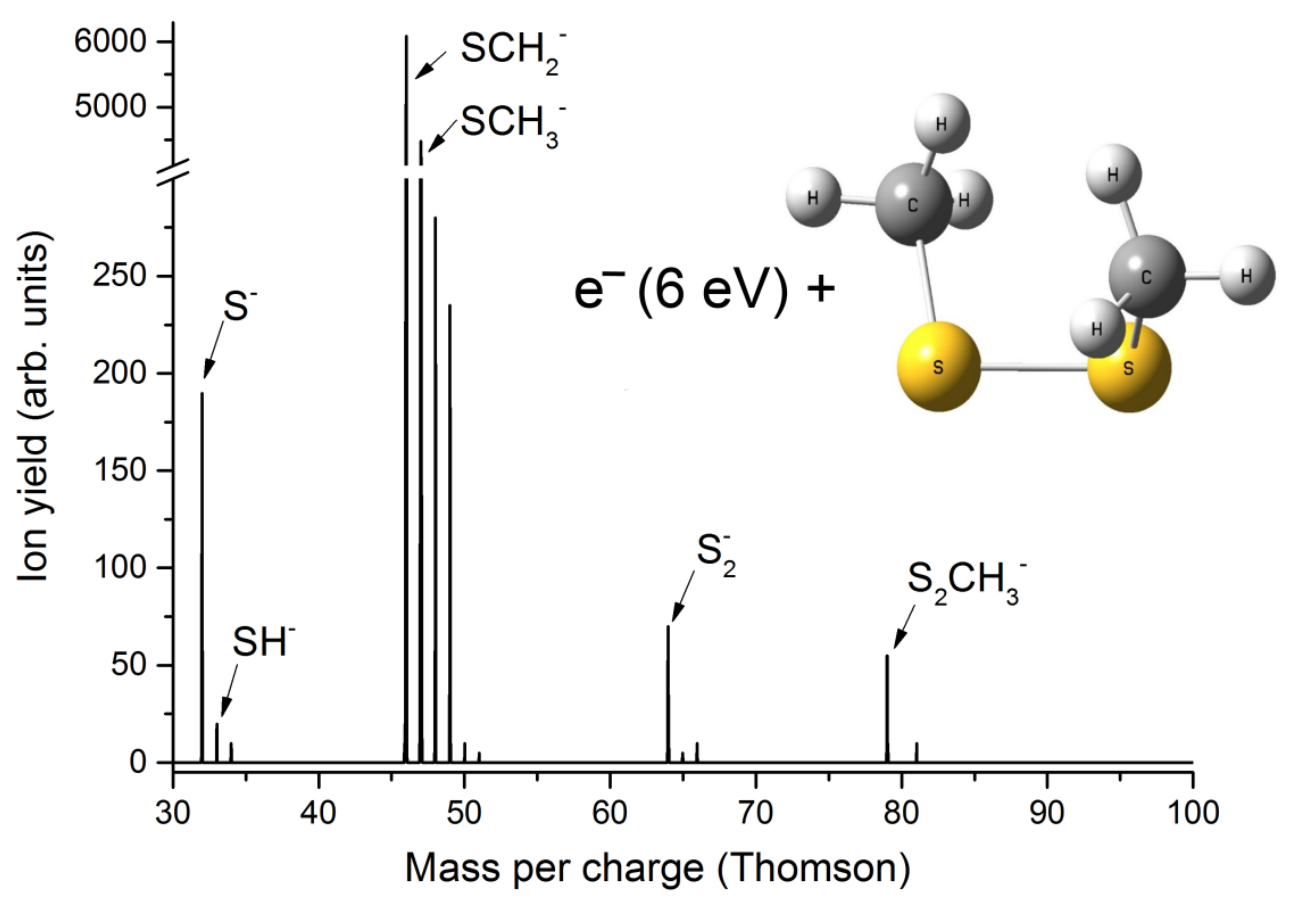




\section{Highlights}

- Electron attachment to $\mathrm{C}_{2} \mathrm{H}_{6} \mathrm{~S}_{2}$ is studied using a high sensitivity mass spectrometer

- Ab-initio calculations are used to identify fragments upon electron attachment

- We observe a variety of dissociation channels including molecular rearrangement 